\title{
Os caminhos percorridos pelo processo inclusivo de alunos com deficiência na escola: uma reflexão dos direitos construídos historicamente
}

\begin{abstract}
Maria Luíza Tanure Alves* Edison Duarte**

\section{Resumo}

O movimento de inclusão defende a educação de qualidade para alunos com deficiência no sistema regular de ensino e as escolas devem fornecer as condições necessárias para que este aluno aprenda. Este texto tem como objetivo trazer uma leitura crítica sobre o processo histórico de inclusão de alunos com deficiência no sistema educacional, com base na análise da legislação oficial publicada sobre o tema. Essa análise permite reflexões a respeito das evoluções conquistadas, bem como os possíveis equívocos ainda presentes. O referido texto se deteve apenas ao período histórico referente à fase de inclusão, com início na década de 1990. A legislação vigente estabelece a adequação do sistema educacional às necessidades e limitações apresentadas pelos alunos com deficiência, transtornos globais de desenvolvimento ou com altas habilidades/superdotação. Os recursos educacionais especiais são limitados apenas aos alunos com essas condições físicas ou psicológicas, legitimadas por laudo médico.
\end{abstract}

Palavras-chave: Inclusão. Pessoa com deficiência. Educação.

\section{History of inclusionary process of students with disability in the school: a reflexion of historically developed rights}

\begin{abstract}
Inclusion group supports high quality education to students with disability within regular educational system. Brazilian laws determine that schools should have necessary conditions to facilitate students' learning. The aim of this paper is to critically review students with disability inclusionary process in Brazilian educational system based on regulating laws. Thus, it will be possible to observe and to think of gradual development, as well as of possible existing mistakes. Only articles referring to inclusionary process itself, which started during 1990's, were reviewed. Current Brazilian educational laws state that educational system should adjust to the needs and limitation of students with disability, general development disorder, or gifted. However, special educational resources are limited only to students with physical and psychological conditions acknowledged by a medical expert.
\end{abstract}

Keywords: Inclusion. Person with disability. Education.

\footnotetext{
* Doutoranda pela Faculdade de Educação Física da UNICAMP, Docente da Faculdade Adventista de Hortolândia, São Paulo, Brasil.

** Docente da Faculdade de Educação Física da UNICAMP, São Paulo, Brasil.
} 
O movimento inclusivo defende que a criança com deficiência deve ser incluída no ensino regular para que possa se desenvolver e participar ativamente da sociedade (LA MASTER et al., 1998; ODOM; DIAMOND, 1998; KARAGIANNIS; STAINBACK; STAINBACK, 1999; STAINBACK ; STAINBACK, 1999; MARCHESI, 2001; RODRIGUES, 2001; PIVIK; MCCOMAS; LAFLAME, 2002). Seu processo educacional deve respeitar suas diferenças e atender suas necessidades educacionais como um todo, permitindo que a criança seja um membro ativo dentro de sua escola (ODOM; DIAMOND, 1998; PLACE ; HODGE, 2001; KODISK et al., 2006).

De acordo com o Censo Escolar/MEC/INEP de 2006, houve um grande crescimento do número de alunos matriculados na educação especial entre os anos de 1998 e 2006. O total de matrículas de alunos com deficiência em classes comuns do ensino regular passou de 43.923 alunos, no ano 1998, para 325.316 em 2006 (crescimento de 640\%). As matrículas na educação especial estão concentradas, principalmente, no ensino fundamental, com $66,5 \%$ de alunos matriculados em 2006. Com relação às outras etapas do ensino regular, $16 \%$ dos alunos encontram-se na educação infantil; $2 \%$ estão no ensino médio; $8,3 \%$ na educação de jovens e adultos; $6,7 \%$ na educação profissional (básico) e $0,28 \%$ na educação profissional (técnico). Na educação superior, foi registrado um aumento do número de matrículas de alunos com deficiência de $136 \%$.

Partindo dessas informações, este texto tem como objetivo principal tecer os caminhos percorridos historicamente pela legislação brasileira para garantir a inclusão do aluno com deficiência no sistema regular de ensino, proporcionando uma leitura crítica sobre o tema. Dessa forma, será possível observar e elaborar reflexões a respeito das evoluções conquistadas ao longo do tempo, bem como os possíveis equívocos ainda presentes. O referido texto se deteve apenas ao período histórico referente à fase de inclusão propriamente dita, com início na década de 1990.

Os primeiros documentos oficiais nacionais e internacionais delineadores do processo inclusivo começam a ser estruturados na década de 1990, com início do processo inclusivo. No ano de 1990, na Conferência Mundial sobre Educação para Todos - Satisfação das Necessidades Básicas de Aprendizagem (Tailândia) - temos o delineamento de um dos desses primeiros documentos relacionados com a educação para todos, a "Declaração Mundial sobre Educação para Todos", que objetiva defender a educação como um direito fundamental de cada cidadão (BRASIL, 1990), sendo um direito básico de homens e mulheres, de todas as idades, no mundo inteiro. Ela nos traz que "a educação básica é mais do que uma finalidade em si mesma. Ela é a base para a aprendizagem e o desenvolvimento humano permanentes, sobre a qual os países podem construir, sistematicamente, níveis e tipos mais adiantados de educação e capacitação" (BRASIL, 1990, p. 4).

Posteriormente, em 1994, temos a Conferência Mundial sobre Necessidades Educativas Especiais, em Salamanca, Espanha. O resultado dessa 
conferência foi o delineamento da Declaração de Salamanca (BRASIL, 1994), documento este que representa uma verdadeira carta magna da mudança de paradigma da escola integrativa para a escola inclusiva (RODRIGUEZ, 2001).

Na Declaração de Salamanca (BRASIL, 1994), são reafirmados os valores da educação para todos, porém com ênfase nas modificações de políticas necessárias para a concretização de uma educação integradora, sobretudo as com necessidades educativas especiais. A Declaração de Salamanca afirmaque:

as escolas deveriam acomodar todas as crianças independentemente de suas condições físicas, intelectuais, sociais, emocionais, lingüísticas ou outras. Elas deveriam incluir crianças deficientes e superdotadas, crianças de rua e que trabalham, crianças de origem remota ou de população nômade, crianças pertencentes a minorias lingüísticas, étnicas ou culturais, e crianças de outros grupos desvantajados ou marginalizados. Tais condições geram uma variedade de diferentes desafios aos sistemas escolares. (BRASIL, 1994, p. 3)

De acordo com a Declaração de Salamanca, o termo necessidades educacionais especiais "refere-se a todas aquelas crianças ou jovens cujas necessidades educacionais especiais se originam em função de deficiências ou dificuldades de aprendizagem" (BRASIL, 1994, p. 3). Estas crianças devem ser educadas dentro do sistema escolar regular de ensino. Para tanto, as escolas devem buscar formas de fornecer-Ihes uma educação de qualidade. Podemos observar que a partir dessa declaração já temos o emprego do conceito de escola inclusiva. Nesse sentido,

o desafio que confronta a escola inclusiva é no que diz respeito ao desenvolvimento de uma pedagogia centrada na criança e capaz de bem sucedidamente educar todas as crianças, incluindo aquelas que possuam desvantagens severa. O mérito de tais escolas não reside somente no fato de que elas sejam capazes de prover uma educação de alta qualidade a todas as crianças: o estabelecimento de tais escolas é um passo crucial no sentido de modificar atitudes discriminatórias, de criar comunidades acolhedoras e de desenvolver uma sociedade inclusiva. (BRASIL, 1994, p. 4)

A Declaração de Salamanca (BRASIL, 1994) descreve também que a "educação especial" incorpora os mais do que comprovados princípios de uma forte pedagogia da qual todas as crianças possam se beneficiar. Ela assume que as diferenças humanas são normais e que há a necessidade de sua adaptação às necessidades de cada criança, ao invés de impelir a adaptação da criança às afirmações pré-concebidas a respeito do ritmo e da natureza do processo de aprendizagem. 
A Declaração de Salamanca (BRASIL, 1994) proclama que:

- Toda criança tem direito fundamental à educação, e deve ser dada a oportunidade de atingir e manter o nível adequado de aprendizagem;

- Toda criança possui características, interesses, habilidades e necessidades de aprendizagem que são únicas;

- Sistemas educacionais deveriam ser designados e programas educacionais deveriam ser implementados no sentido de se levar em conta a vasta diversidade de tais características e necessidades;

- Aqueles com necessidades educacionais especiais devem ter acesso à escola regular, que deveria acomodá-los dentro de uma pedagogia centrada na criança, capaz de satisfazer a tais necessidades;

- Escolas regulares que possuam tal orientação inclusiva constituem os meios mais eficazes de combater atitudes discriminatórias, criando-se comunidades acolhedoras, construindo uma sociedade inclusiva e alcançando educação para todos; além disso, tais escolas proveem uma educação efetiva à maioria das crianças e aprimoram a eficiência e, em última instância, o custo da eficácia de todo o sistema educacional.

A Declaração de Salamanca funciona como um conjunto de diretrizes para a implantação e o direcionamento das práticas inclusivistas no âmbito educacional. É importante notar que o processo de inclusão, nesse documento, é defendido para todas as crianças, independente de suas condições físicas, suas origens ou problemas de aprendizagem. Para tanto, a proposta pedagógica da escola deve dar condições para o aprendizado de qualidade para todos.

No que concerne às políticas educacionais nacionais, temos, segundo Lima e Duarte (2001), no texto da Constituição Federal de 1988, art. 205, a educação como um direito de todos e dever do estado e da família. No art. 206, temos alguns princípios norteadores para a educação, dentre os quais estão: a igualdade de convicções não só para o acesso, mas também para a permanência na escola; a liberdade de aprender, ensinar e divulgar o pensamento; o pluralismo de ideias e concepções pedagógicas; a coexistência de instituições públicas e privadas; a existência de ensino público gratuito e a gestão democrática do ensino público.

A Constituição Federal de 1988 (BRASIL, 1988) é um dos primeiros documentos oficiais que garantem o direito à educação para todos. Apesar de garantir o direito à educação, este documento não garante formas de atendimento às necessidades educacionais específicas das crianças com deficiência ou com qualquer outro tipo de condição que dificulte a aprendizagem. Neste momento histórico, fica definido o direito ao acesso à escola, mas não ao processo de aprendizagem. Talvez essa condição tenha sido reflexo do movimento de integração presente na época. 
O movimento de integração teve seu início na década de 1960. Este movimento tinha como objetivo inserir socialmente aquelas pessoas com deficiência que alcançaram um nível de competência compatível com os padrões sociais vigentes. Havia participação social apenas das pessoas com deficiência que conseguissem responder às limitações e exigências impostas pela sociedade, como as barreiras físicas, atitudinais e programáticas existentes. $\mathrm{O}$ movimento de integração foi substituído pelo movimento de inclusão na década de 1990 (STAINBACK; STAINBACK, 1999).

Posteriormente a este documento, temos a Lei de Diretrizes e Bases (Lei n. 9394 ou Lei Darcy Ribeiro) vigente desde 1996, que regulamenta e dá diretrizes sobre a educação nacional. Essa lei disciplina a educação escolar, que se desenvolve, predominantemente, por meio do ensino em instituições próprias, devendo estar vinculada ao mundo do trabalho e a prática social. Em seu art. 2, ela define que a educação é dever da família e do Estado, inspirada nos princípios de liberdade e nos ideais de solidariedade humana e tem por finalidade o pleno desenvolvimento do educando, seu preparo para o exercício da cidadania e sua qualificação para o trabalho (BRASIL,1996).

Com relação à educação das pessoas com deficiência, temos todo um capítulo dedicado a este tema (capítulo V), o qual define educação especial como a "modalidade de educação escolar, oferecida preferencialmente na rede regular de ensino, para educandos portadores de necessidades especiais" (BRASIL, 1996, p. 17). Fica também estabelecido que devam ser oferecidos serviços de apoio especializados na escola regular para atender às necessidades dos alunos com deficiência. No entanto, o aluno com deficiência deve ser atendido em classes, escolas ou serviços especiais sempre que não for possível sua inclusão nas classes de ensino regular. A oferta de educação especial deve ter início na faixa etária de zero a seis anos durante a educação infantil (BRASIL, 1996).

Ainda com relação à Lei de Diretrizes e Bases, Lei n. 9394 ou Lei Darcy Ribeiro (capítulo V), fica assegurado aos alunos com deficiência o direito à:

- Currículos, métodos, técnicas, recursos educativos e organização específica para atender às suas necessidades;

- Adequação dos objetivos e ritmo de ensino para aqueles que não apresentarem capacidade de atingir o nível exigido para conclusão do ensino fundamental ou que necessitarem de aceleração para sua conclusão em menor tempo;

- Professores capacitados para atendimento em serviços especializados, bem como para sua inclusão em classes regulares;

- Educação voltada para trabalho profissional;

- Acesso igualitário aos programas sociais disponíveis para seu respectivo nível de ensino (BRASIL, 1996). 
A Lei de Diretrizes e Bases aparece como o primeiro documento oficial nacional delineador das condições de ensino específicas para atendimento das dificuldades de aprendizagem dos alunos com deficiência. Esta é uma tentativa de garantir o acesso à escola e ao conhecimento oferecido. Neste momento, o foco do processo inclusivo concentra-se apenas no acesso e aprendizagem dos conteúdos escolares, eximindo-se de responsabilidades sobre a interação social do aluno com deficiência na escola. A educação especial é definida como uma modalidade de ensino, permitindo a sua compreensão como modalidade de ensino paralela às outras já existentes (infantil, fundamental, médio, superior e profissionalizante). Nota-se que, apesar de se definir o alunoalvo da educação especial como sendo aquele com necessidades educacionais especiais, ainda não há uma definição restrita do termo e sua abrangência. Outro ponto importante consiste no primeiro reconhecimento da necessidade de capacitação profissional, apesar de não ser definida a forma como esta deva ocorrer.

Em dezembro de 1999, temos a publicação do Decreto Lei n. 3298 (regulamenta a Lei n. 7853 de outubro de 1989) que dispõe sobre a Política Nacional para Integração da Pessoa Portadora de Deficiência (BRASIL, 1999). Seu objetivo é assegurar o pleno exercício dos direitos individuais e sociais das pessoas com deficiência. Em seu Capítulo VII - Da equiparação de oportunidades, na Seção II - Educação, temos os princípios que regem o direito à educação para pessoas com deficiência.

Nesse documento, a educação especial é definida como "modalidade de educação escolar oferecida preferencialmente na rede regular de ensino para educando com necessidades educacionais especiais, entre eles o portador de deficiência" (BRASIL, 1999, p. 8). Esta deve ser compreendida como uma modalidade transversal a todos os níveis e modalidades de ensino, com papel de complementar a educação regular. Nesse momento, a compreensão de necessidades educacionais especiais já ultrapassa o aluno com deficiência, entendendo-se a abrangência entre estes e outros alunos com dificuldades de aprendizagem não decorrentes de algum tipo de deficiência. No entanto, durante todo o texto, as modificações estruturais, metodológicas e didáticas são previstas apenas para alunos com deficiência.

De maneira geral, fica definido que as pessoas com deficiência têm direito àeducação em escolas regulares, nos níveis básico, médio, fundamental, universitário e profissionalizante. Devem ser oferecidos serviços de educação especial para o educando com deficiência, bem com condições físicas e pedagógicas para que ele consiga participar e acompanhar a vida escolar. O oferecimento da educação especial deve ter início na educação infantil (zero a seis anos de idade) e continuar até o ensino superior (BRASIL, 1999).

Complementando essas medidas, temos as Diretrizes para a Educação Especial na Educação Básica, Resolução CNE/CEB n. 2/2001 (BRASIL, 2001a), que defende inclusão como a reestruturação do sistema educacional 
para que a escola se torne um ambiente democrático e competente para o trabalho com todos os alunos, sem distinção entre eles de qualquer tipo. $O$ documento descreve a educação especial como modalidade da educação escolar, definida em uma proposta pedagógica, que tem como meta apoiar, complementar, suplementar e, até mesmo, substituir os serviços educacionais regulares para que as necessidades educacionais de seus educandos sejam atendidas em todas as etapas do sistema de ensino (BRASIL, 2001a). A definição da educação especial em proposta pedagógica, neste momento, traz um novo momento para a educação inclusiva, no qual há o reconhecimento que as necessidade educacionais dos alunos precisam ser atendidas com base em um proposta pedagógica concreta, e não apenas o acesso ao ensino sem sentido para o aluno.

As Diretrizes para a Educação Especial na Educação Básica (BRASIL, 2001a) asseguram que o atendimento ao aluno com deficiência deve começar já na educação infantil, creches e pré-escolas. Estes alunos devem ser educados em classes comuns do ensino regular em todas as etapas do sistema de ensino, ficando garantido o seu atendimento em classes especiais, caso seja necessário devido às dificuldades ou limitações apresentadas. As escolas também devem oferecer condições de acessibilidade, com eliminação das barreiras arquitetônicas em sua edificação e nos seus meios de transporte, bem como acessibilidade aos conteúdos curriculares aos alunos com dificuldade de comunicação, com emprego da língua de sinais e sistema Braille.

Ainda no ano de 2001 há a publicação, pelo governo federal, do Plano Nacional de Educação (PNE) (BRASIL, 2001b), que tem como função estabelecer as diretrizes da educação nacional em todos os níveis e modalidades de ensino. No tocante à educação especial, o PNE define como diretrizes o atendimento educacional especializado na rede regular de ensino para todos aqueles com necessidades educacionais especiais originadas de deficiências físicas, sensoriais, intelectuais ou múltiplas, bem como por altas habilidades/ superdotação.

É responsabilidade do governo federal, estadual e municipal o oferecimento de educação de qualidade para estes alunos, com adequação de espaço físico, equipamentos e qualificação dos professores. O ensino educacional especializado deve estar atrelado a serviços de saúde e assistência para potencializar seu desenvolvimento. Deve haver ainda formação de recursos humanos capacitados para o trabalho com alunos com deficiência, oferecendo-se conteúdos sobre educação especial durante os cursos de formação dos professores. Neste ponto, há um grande avanço, visto que é defendida a capacitação de todos os profissionais envolvidos com a educação deste aluno, e não apenas do professor (BRASIL, 2001).

Aliado aos documentos mencionados, ainda temos a Resolução CNE/ CP n. 01/2002, a Lei n. 10.436/02 e a Portaria n. 2.678/02. A Resolução CNE/ CP n. 01/2002, que define as diretrizes curriculares nacionais para formação de 
professores da educação básica, assegura que as instituições de ensino devem prover a formação de docentes voltada para a diversidade, com conhecimentos sobre as necessidades educacionais dos alunos. A Lei n. 10.436/02 reconhece a língua de sinais como meio legal de comunicação e expressão, e determina sua inclusão como disciplina na formação de professores e fonoaudiólogos. Já a Portaria n. 2.678/02 determina normas e diretrizes para utilização do sistema Braille nas diversas modalidades do sistema de ensino (BRASIL, 2008b). De forma geral, esses documentos têm como meta concretizar os objetivos delineados de capacitação profissional para sua atuação com alunos com deficiência. Dá-se início, então, à estruturação de disciplinas relacionadas com a educação especial nos cursos de graduação e licenciaturas.

Ainda no âmbito do direito ao acesso à educação inclusiva, em 2008, o governo federal aprovou o Decreto Legislativo 186/08 (BRASIL, 2008a) que aprova o texto da Convenção sobre os Direitos das Pessoas com Deficiência e de seu protocolo facultativo (promulgada pela Assembleia Geral das Nações Unidas, ONU, em 2006). No texto desse documento, fica estabelecido que as "pessoas com deficiência devem ter acesso ao sistema fundamental de ensino, de qualidade e gratuito, em igualdade de condições com as demais pessoas nas comunidades em que vivem" (BRASIL, 2008a, p. 14). A Convenção sobre os direitos das pessoas com deficiência define que pessoas com deficiência "são aquelas que têm impedimentos de natureza física, intelectual ou sensorial, os quais, em interação com diversas barreiras, podem obstruir sua participação plena e efetiva na sociedade com as demais pessoas" (BRASIL, 2008a, p. 3).

Nesse documento, fica definido que as pessoas com deficiência devem receber o apoio necessário para sua efetiva educação no sistema regular de ensino, com as adaptações necessárias para tal. Define também que o aluno com deficiência deve ter acesso à educação em igualdade de oportunidades com os demais em todos os níveis de ensino (infantil, fundamental, médio, superior e profissionalizante) e que devem ser oferecidas formas alternativas de comunicação e linguagem, como a escrita em braille e comunicação em libras, para os alunos que desta necessitarem. Para tal, devem ser formados professores especializados para a tarefa, incluindo-se aqueles professores com deficiência (BRASIL, 2008a).

De forma geral, esse documento vem garantir o direito à educação de qualidade para a pessoa com deficiência. Sua objetivo principal não é definir formas ou metas para concretização da educação inclusiva, mas garantir o direito do aluno com deficiência ao seu acesso. Fica estabelecido apenas o direito às adaptações e apoio especializados para aqueles alunos com deficiência, caracterizados por laudo médico. No entanto, o texto não contradiz a necessidade deste atendimento educacional especializado para alunos com outra natureza de impedimento. O texto tem como objetivo garantir o direito à educação de qualidade para aqueles com deficiência, não impedindo que os recursos educacionais especiais sejam fornecidos a outros alunos. 
A Política Nacional de Educação Especial na Perspectiva da Educação Inclusiva (BRASIL, 2008b), publicada em 2008, vem complementar o texto da Convenção sobre os Direitos das Pessoas com Deficiência aprovado na forma do decreto 186/09 (BRASIL, 2008a). Em seu texto, este documento tem como meta garantir: 1) o acesso ao ensino regular com participação, aprendizagem e continuidade dos estudos nos níveis seguintes; 2) atuação da educação especial em todos os níveis de ensino; 3 ) atendimento educacional especializado; 4) formação especializada de professores para atuação no atendimento educacional especializado; 5) acessibilidade arquitetônica e, finalmente, 6) articulação entre os diversos setores para implementação de políticas públicas (BRASIL, 2008b).

A Política Nacional de Educação Especial na Perspectiva da Educação Inclusiva (BRASIL, 2008b) afirma que a educação especial faz parte da proposta pedagógica da escola e tem como público-alvo além dos alunos com deficiência também aqueles com transtornos globais do desenvolvimento e alunos com altas habilidades/superdotação. $O$ referido documento define

\begin{abstract}
alunos com deficiência àqueles que têm impedimentos de longo prazo, de natureza física, mental, intelectual ou sensorial, que em interação com diversas barreiras podem ter restringida sua participação plena e efetiva na escola e na sociedade. Os alunos com transtornos globais do desenvolvimento são aqueles que apresentam alterações qualitativas das interações sociais recíprocas e na comunicação, um repertório de interesses e atividades restrito, estereotipado e repetitivo. Incluemse nesse grupo alunos com autismo, síndromes do espectro do autismo e psicose infantil. Alunos com altas habilidades/superdotação demonstram potencial elevado em qualquer uma das seguintes áreas, isoladas ou combinadas: intelectual, acadêmica, liderança, psicomotricidade e artes. (BRASIL, 2008, p. 15)
\end{abstract}

A escola deve oferecer aos alunos com deficiência, transtornos globais de desenvolvimento e altas habilidades/superdotação o atendimento educacional especializado. Seu oferecimento é obrigatório, devendo ocorrer no turno inverso ao frequentado pelo aluno com deficiência na classe regular. $O$ atendimento educacional especializado tem como meta disponibilizar serviços e recursos próprios para o atendimento das necessidades educacionais destes alunos. Seu propósito é identificar, elaborar e organizar recursos pedagógicos e de acessibilidade de acordo com as necessidades e limitações do aluno. Sendo assim, o atendimento educacional especializado não tem como objetivo substituir os conteúdos do ensino regular, mas complementar ou suplementá-lo (BRASIL, 2008b).

Dessa forma, fica estabelecido que o direito aos recursos pedagógicos, estruturais, metodológicos e de acessibilidade da educação especial se 
restringem aos alunos com deficiência, transtornos globais de desenvolvimento, ou aqueles com altas habilidades/superdotação. Neste ponto, o documento legitima as dificuldades de aprendizagem e sucesso escolar apenas daqueles alunos com problemas médicos e psicológicos, comprovados por um laudo médico. Este tipo de proposta cria dois tipos de aluno na escola: aqueles com necessidades educacionais especiais (com direito a atendimento educacional especializado e adaptações de acordo com sua necessidade) e aqueles com necessidades educacionais normais (com direito ao currículo convencional) (RODRIGUES, 2001). Esta concepção vai contra aos princípios defendidos pela Declaração de Salamanca, a qual descreve o dever da escola em "incluir crianças deficientes e superdotadas, crianças de rua e que trabalham, crianças de origem remota ou de população nômade, crianças pertencentes a minorias lingüísticas, étnicas ou culturais, e crianças de outros grupos desvantajados ou marginalizados" (BRASIL, 1994, p. 3). É importante frisar que a inclusão, neste caso, não é apenas a defesa do acesso e frequência à escola, mas também a uma educação de qualidade.

As definições e delimitações acerca do aluno a ser atendido pela educação especial, empregadas nos documentos oficias aqui descritos, demonstram a grande preocupação do governo federal em estabelecer, de forma clara, 0 público-alvo do processo inclusivo na escola. No entanto, o foco da educação especial no processo inclusivo apenas de alunos com deficiência, transtornos globais de desenvolvimento ou alunos com altas habilidades/superdotação (BRASIL, 2008b) pode impedir a visão completa pelo professor das necessidades e limitações dos demais alunos, já que este fica preso aos rótulos estabelecidos pela política educacional adotada atualmente. Deve-se ressaltar que o processo inclusivo deve ser proporcionado a todos os alunos da escola, independente das definições e rótulos empregados pela política educacional, visto que os alunos com limitações e necessidades especiais ultrapassam as barreiras das definições encontradas nos documentos oficiais.

As exigências de adaptação dos métodos de ensino para atendimento das necessidades e limitações dos alunos da educação especial impostas pelo governo federal devem ser vistas como uma necessidade de todo o sistema regular de ensino, e não apenas dos alunos da educação especial. A forma como a educação especial é abordada nos documentos oficias permite o entendimento da necessidade de adaptação dos métodos, objetivos, materiais e conteúdos apenas para aqueles definidos como seus alunos-alvo. No entanto, isto nos faz pensar na seguinte questão: quem é esse aluno do sistema regular de ensino que nunca precisou de algum tipo de adaptação no método, recurso, atividade, objetivos ou conteúdos para participar da aula? A simples observação da realidade encontrada dentro das salas de aula nos mostra que todos os alunos, em algum momento, demonstrarão algum tipo de necessidade ou limitação. Estas podem estar vinculadas ao conteúdo ministrado, e não necessariamente à presença de deficiência ou distúrbios de desenvolvimento no aluno. 
Isso é notável em alunos que apresentam um desempenho muito bom em determinado conteúdo curricular, mas que, em outro conteúdo, precisam de atividades e ajuda extra dos professores. Os objetivos e métodos adotados pela educação especial devem ser uma constante também no sistema regular de ensino. Se pensarmos assim, faz-se desnecessária a separação estruturada entre os mesmos. O sistema regular de ensino deve incorporar, em sua estrutura, as exigências adotadas pela educação especial para atendimento das necessidades dos alunos, fazendo, assim, que deixem de existir alunos da educação especial e passem a existir apenas alunos.

\section{Referências}

BRASIL. Constituição da República Federativa do Brasil de 1988. 1988.

Declaração mundial sobre educação para todos: plano de ação para satisfazer as necessidades básicas de aprendizagem. Jomtiem/Tailândia: UNESCO, 1990.

Declaração de Salamanca e linha de ação sobre necessidades educativas especiais. Brasília: UNESCO, 1994.

LDB 9.394, de 20 de dezembro de 1996: Lei de Diretrizes e Bases da Educação Nacional. 1996.

Decreto Lei n. 3298, de 20 de dezembro de 1999. 1999.

Diretrizes Nacionais para a Educação Especial na Educação Básica. Brasília: MEC/SEESP, 2001a.

Plano Nacional de Educação - PNE. Brasília: INEP, 2001b.

Decreto n. 186, de 9 julho de 2008. Aprova o texto da Convenção sobre os Direitos das Pessoas com Deficiência e de seu Protocolo Facultativo. 2008a.

Política Nacional de Educação Especial na Perspectiva da Educação Inclusiva. Brasília: MEC/SEESP, 2008b.

Plano Nacional de Educação - PNE. Brasília: INEP, 2001.

KARAGIANNIS, A.; STAINBACK, W.; STAINBACK, S. Fundamentos Do ensino inclusivo. In: STAINBACK, W.; STAINBACK, S. (Ed.). Inclusão: um guia para educadores. Porto Alegre: Artmed, 1999, p. 35-47.

KODISK, S. et al. Determinants of physical activity in an inclusive setting. Adapted Physical Activity Quartely, v. 23, p. 390-409, 2006.

LA MASTER, K. et al. Inclusion pratices of effective elementary specialists. Adapted Physical Activity Quartely, v. 15, p. 64-81, 1998.

LIMA, S. T.; DUARTE, E. Educação Física e a escola inclusiva. SOBAMA:Temas em Educação Física Adaptada, 2001. 
MARCHESI, A. A. Prática das escolas inclusivas. In: RODRIGUES, D. (Ed.). Educação e diferença: valores e práticas para uma educação inclusiva. Portugal: Porto, 2001. p. 93-108.

ODOM, S. L.; DIAMOND, K. E. Inclusion of young children with special deficiênciads in early childhood education: the research base. Early Childhood Research Quartely, v. 13, n. 1, p. 3-25, 1998.

PIVIK, J.; MCCOMAS, J.; LAFLAME, M. Barriers and facilitators to inclusive education. Exceptional Children, v. 69, n. 1, p. 97-107, 2002.

PLACE, K.; HODGE, S. R. Social inclusion of students with physical disabilities in general physical education: a behavioral analyses. Adapted Physical Activity Quartely, v. 18, p. 389-404, 2001.

RODRIGUES, D. A. (Ed.) Inclusão e educação: doze olhares sobre a educação inclusiva. São Paulo: Sumused. 2001.

RODRIGUEZ, D. A. Educação e a diferença. In: Educação e diferença: valores e práticas para uma educação inclusiva. Portugal: Porto , 2001. p. $17-45$.

STAINBACK, W.; STAINBACK, S. Colaboração, Rede de apoio e construção de comunidade. In: STAINBACK, W.; STAINBACK, S. (Ed.). Inclusão: um guia para educadores. Porto Alegre: Artes Médicas, 1999. p. 223-230.

\section{Correspondência}

Maria Luíza Tanure Alves - Rua dos Americanos, 838, apt. 65, Barra Funda, CEP: 01138-010 - São Paulo, Brasil.

E-mail: luizatanure@gmail.com - edison@fef.unicamp.br 